\title{
Factors to be considered in designing a faculty development program for medical education: local experience from the Western region of Saudi Arabia
}

\author{
Hussein Algahtani ${ }^{1}$, Bader Shirah ${ }^{2}$, Lana Alshawwa ${ }^{3}$, Ara Tekian ${ }^{4}$, John Norcini $^{5}$ \\ ${ }^{1}$ Neurology Section, Department of Medicine, King Saud bin Abdulaziz University for Health Sciences, King Abdulaziz Medical City, Jeddah, \\ Saudi Arabia \\ ${ }^{2}$ King Abdullah International Medical Research Center, King Saud bin Abdulaziz University for Health Sciences, Jeddah, Saudi Arabia \\ ${ }^{3}$ Department of Medical Education, King Abdulaziz University, Jeddah, Saudi Arabia \\ ${ }^{4}$ Department of Medical Education, University of Illinois at Chicago, Chicago, IL, USA \\ ${ }^{5}$ Foundation for Advancement of International Medical Education and Research, Philadelphia, PA, USA
}

Received: March 4, 2020

Revised: April 1, 2020

Accepted: April 10, 2020

Corresponding author:

Hussein Algahtani

Neurology Section, Department of

Medicine, King Saud bin Abdulaziz

University for Health Sciences, King

Abdulaziz Medical City, Jeddah

21483, Saudi Arabia

Tel: +966-556633130

E-mail: halgahtani@hotmail.com

\begin{abstract}
Background: Among the different aims of medical education, the provision of society with skilled, professional, and knowledgeable healthcare workers who maintain and develop their expertise over a lifetime career is important. The achievement of this goal is linked with the professional development of both faculty members and healthcare workers. This study aims to measure the perception of faculty members regarding their views about the goals of faculty development programs, practices and activities, and factors that determine their achievement.

Methods: A cross-sectional survey was conducted in multiple universities in the Western region of Saudi Arabia. The participants were given a pre-designed self-administered questionnaire generated from literature. The survey questionnaire consisted of three sections that were designed to assess the faculty members' perception on the faculty development program.

Results: A total of 210 faculty members participated in the study. The most important perceived goal was to motivate teachers to become better teachers. The most important perceived practice was establishing a positive climate for teaching and learning. The most important perceived factor was skilled and dedicated staff support.

Conclusion: The results of this study demonstrate that faculty members have positive perceptions regarding all aspects of faculty development programs. This study will raise awareness regarding the importance of faculty development programs in sustaining educational vitality. We recommend the implementation and maintenance of comprehensive faculty development programs in Saudi universities.
\end{abstract}

Keywords: Faculty; Medical education; Program development; Saudi Arabia

\section{Introduction}

Medical education in Saudi Arabia has come a long way since its inception, and continued progress will rely on faculty development, which encompasses all formal and informal activities of health professionals who pursue to improve their knowledge,

Copyright (C) 2020 Yeungnam University College of Medicine

This is an Open Access article distributed under the terms of the Creative Commons Attribution Non-Commercial License (http://creativecommons.org/licenses/by-nc/4.0/) which permits unrestricted non-commercial use, distribution, and reproduction in any medium, provided the original work is properly cited. 
skills, and behaviors in both individual and group settings. The need for faculty development programs is crucial in medical schools in Saudi Arabia for several reasons. First, throughout the last decade, there has been a tremendous increase in the number of medical students, which will drive demand for quality medical education $[1,2]$. Second, fast paced innovations in medical education have taken place over the last two decades, and it is critical to keep up with them $[3,4]$. Third, continuous changes in learning methods have occurred (e.g., adaptation of learning theories in the methodology of teaching, e-learning, simulation, etc.), and faculty need to be aware of them [5]. Fourth, continuous advancement of technology in medical treatment and management have occurred, and students must receive training in them. Fifth, new assessment methods and tools have been developed (e.g., objective structured clinical examination [OSCE], objective structured practical examination [OSPE], mini-clinical evaluation exercise $[\mathrm{miniCEX}])$, and their appropriate application underpins high quality patient care. Additionally, there are other compelling factors that could possibly affect the performance of faculty members. These include the absence of formal training in academic roles, multicultural distribution of faculty members in the department, different orientations and practices in regard to teaching methodologies, multiple professional job roles (e.g., physician, educator, researcher), heavy workloads, different work assignment (e.g., lecturer, committee chairman), and numerous professional and personal appointments [6-10]. Faculty development programs need to address these issues.

In 2010, the world celebrated the centenary of Abraham Flexner's seminal report on the transformation of American medical schools. This report established the structure of the basic medical education in existence today [11]. Medical education is a lifelong affair with its three different phases — undergraduate, postgraduate, and continuing professional development of practicing clinicians. Among the different aims of medical education, the provision of society with skilled, professional, and knowledgeable healthcare workers who maintain and develop their expertise over a lifetime career is important. The achievement of this goal is linked with the professional development of both faculty members and healthcare workers [12]. In this study, we tried to measure the perception of faculty members from multiple universities in the Western region of Saudi Arabia regarding their views about the goals of the faculty development program, practices and activities, and factors that determine their achievement.

\section{Materials and methods}

The Institutional Review Board (IRB) of King Abdullah Interna- tional Medical Research Center (KAIMRC) approved this study (IRB No: IRBC/430/16).

A cross-sectional survey was conducted in six universities in the Western region of Saudi Arabia. Data collection began in August 2016 and was completed in August 2017. Inclusion criteria included faculty members who were employed full-time or joint appointees, working for the last two years, teaching with or without clinical teaching assignments, and had attended or participated in any faculty development program. This sample included different levels of teachers (clinical and pre-clinical) with variable experience. Faculty members who were newly employed, part-timers, and under the non-teaching category were excluded from the study. This study employed the consecutive sampling technique in the selection of respondents based on the eligibility criteria.

The participants were given a pre-designed self-administered questionnaire generated from the literature $[7-10,13,14]$. The survey questionnaire was personally distributed among the respondents to be able to maximize the number of completed questionnaires and allow respondents to ask questions. In order to improve the response rate of faculty members, the purpose of the study and its impact on improving the faculty development program were explained with each distributed questionnaire.

The survey questionnaire consisted of three sections that were designed to assess the faculty members' perception on the faculty development program. These sections captured (1) the respondents' views about the stated goals of the faculty development program, (2) practices and activities, and (3) factors that determine whether program goals have been achieved. The questionnaire utilized a five-point Likert scale with five scaled options per item ( 1 , not at all important; 2 , not very important; 3 , moderately important; 4, important; 5 , very important). In addition, a demographic profile of the participants was collected to identify their backgrounds and work experience that might influence their perceptions of the faculty development program.

To ensure the content validity of the questionnaire, it was initially submitted to a panel of experts in the faculty development program for review, and modifications were made accordingly. A pilot testing was conducted, and Chronbach $\alpha$ for internal consistency was calculated, which demonstrated high reliability. In addition, factor analysis was performed to determine the questionnaires' scales and subscales consistency.

Data were collected and analyzed using the IBM SPSS version 23.0 (IBM Corp., Armonk, NY, USA). Descriptive statistics, such as means, median, and standard deviation, were used to summarize quantitative variables like age. Qualitative variables, such as sex, were summarized using frequencies and percentages.

To ensure the confidentiality of information, all questionnaires 
were anonymous. Furthermore, the cover page of each questionnaire explained the confidentiality issues, included instructions on how to complete the questionnaire, and participants' consent to participate in the study was taken into account.

\section{Results}

A total of 210 faculty members participated in the study. The majority of the participants (56.7\%; 119 participants) were from King Saud bin Abdulaziz University for Health Sciences, followed by Batterjee College (13.8\%; 29 participants), Taif University (10.5\%; 22 participants), Ibn Sina National College for Medical Studies (8.6\%; 18 participants), Umm Al-Qura University (7.1\%; 15 participants), and Rabigh University (3.3\%; 7 participants). The majority were full-time faculty members representing $81.4 \%$ of the total sample. Most of the participants were above 40 years of age ( 169 participants) representing $80.5 \%$. The sex distribution showed that the majority of the participants were males (158 participants) representing $75.2 \%$, while only $50(23.8 \%)$ were females, and two (1\%) did not specify their sex. More than $50 \%$ of the participants were $\mathrm{PhD}$ holders (67.1\%; 141 participants), followed by master's degree (21\%; 44 participants), and bachelor's degree holders ( $9 \% ; 19$ participants). The distribution of academic positions of the participants showed that 114 (54.3\%) were assistant professors, 39 associate professors (18.6\%), 32 professors (15.2\%), 18 lecturers (8.6\%), and seven teaching assistants (3.3\%). Regarding the length of teaching experience, 110 participants (52.4\%) had experience of between 3 and 10 years, 33 (15.7\%) had less than 2 years of teaching experience, and only 21 (10\%) had more than 20 years of teaching experience (Table 1 ).

As shown in Table 2, the faculty members' views about the stated goals of the faculty development program, the most important perceived goal was to motivate teachers to become better teachers ( $4.73 \pm 2.99)$, followed by improving students' learning $(4.51 \pm 0.74)$ and enhancing the value of teaching effectiveness $(4.47 \pm 0.63)$. The items that were evaluated as important but were least highly rated were to serve personal needs $(3.83 \pm 1.01)$, to facilitate effective pedagogy $(4.07 \pm 0.81)$, and to foster faculty career development $(4.09 \pm 0.83)$.

As shown in Table 3, the faculty members' perception of the faculty development program practices and activities, the most important perceived practice was establishing a positive climate for teaching and learning $(4.45 \pm 0.71)$, followed by providing resources $(4.37 \pm 0.71)$ and teaching improvement workshops $(4.31 \pm 0.78)$. The items that were evaluated as important but were the least highly rated were providing faculty mentoring (3.91 \pm 0.84$)$, personal assessment program $(4.02 \pm 0.85)$, and
Table 1. Demographic profile of the participants

\begin{tabular}{|c|c|}
\hline Item & Frequency (\%) \\
\hline \multicolumn{2}{|l|}{ Name of university } \\
\hline KSAU-HS & $119(56.7)$ \\
\hline $\mathrm{BC}$ & $29(13.8)$ \\
\hline TU & $22(10.5)$ \\
\hline ISNCMS & $18(8.6)$ \\
\hline UQU & $15(7.1)$ \\
\hline $\mathrm{RU}$ & $7(3.3)$ \\
\hline \multicolumn{2}{|l|}{ Employment status } \\
\hline Full time & $171(81.4)$ \\
\hline Joint appointees & 39 (18.6) \\
\hline \multicolumn{2}{|l|}{ Age range (yr) } \\
\hline $25-30$ & $4(1.9)$ \\
\hline $31-35$ & $9(4.3)$ \\
\hline $36-40$ & $26(12.4)$ \\
\hline $41-45$ & $64(30.5)$ \\
\hline $46-50$ & $51(24.3)$ \\
\hline$\geq 51$ & $54(25.7)$ \\
\hline Unclassified & $2(1.0)$ \\
\hline \multicolumn{2}{|l|}{ Sex } \\
\hline Male & $158(75.2)$ \\
\hline Female & $50(23.8)$ \\
\hline Unclassified & $2(1.0)$ \\
\hline \multicolumn{2}{|l|}{ Educational attainment } \\
\hline Bachelor & $19(9.0)$ \\
\hline Master & $44(21.0)$ \\
\hline $\mathrm{PhD}$ & $141(67.1)$ \\
\hline Unclassified & $6(2.9)$ \\
\hline \multicolumn{2}{|l|}{ Academic position } \\
\hline Teaching assistant & $7(3.3)$ \\
\hline Lecturer & $18(8.6)$ \\
\hline Assistant professor & $114(54.3)$ \\
\hline Associate professor & $39(18.6)$ \\
\hline Professor & $32(15.2)$ \\
\hline \multicolumn{2}{|c|}{ Length of teaching experience (yr) } \\
\hline$\leq 2$ & $33(15.7)$ \\
\hline $3-5$ & $61(29.1)$ \\
\hline $6-10$ & $49(23.3)$ \\
\hline $11-15$ & $22(10.5)$ \\
\hline $16-20$ & $20(9.5)$ \\
\hline $21-35$ & $21(10.0)$ \\
\hline Unclassified & $4(1.9)$ \\
\hline
\end{tabular}

KSAU-HS, King Saud bin Abdulaziz University for Health Sciences; BC, Batterjee College; TU, Taif University; ISNCMS, Ibn Sina National College for Medical Studies; UQU, Umm Al-Qura University; RU, Rabigh University.

being visible and accessible $(4.05 \pm 0.93)$.

As shown in Table 4, the faculty members' perception of factors that determine whether the goals of the faculty development pro- 
Table 2. Level of importance of the following goals to the faculty development program

\begin{tabular}{llcc}
\hline Rank & \multicolumn{1}{c}{ Goal } & Mean \pm SD & Verbal interpretation \\
\hline 1 & To motivate teachers to become better teacher & $4.73 \pm 2.99$ & Very important \\
2 & To improve students learning & $4.51 \pm 0.74$ & Very important \\
3 & To enhance value of teaching effectiveness & $4.47 \pm 0.63$ & Very important \\
4 & To help faculty member learn excellent teaching & $4.42 \pm 0.78$ & Very important \\
5 & To focus on teaching that are set on high standards & $4.38 \pm 0.71$ & Very important \\
6 & To provide faculty development programs & $4.36 \pm 0.66$ & Very important \\
7 & To build and develop the culture of teaching & $4.34 \pm 0.72$ & Very important \\
8 & To provide skills training & $4.33 \pm 0.73$ & Very important \\
9 & To introduce different teaching strategies & $4.31 \pm 0.80$ & Very important \\
10 & To improve the learning environment & $4.30 \pm 0.74$ & Very important \\
11 & To create a climate of excellent teaching & $4.28 \pm 0.79$ & Very important \\
12 & To improve faculty evaluations & $4.25 \pm 0.87$ & Very important \\
13 & To create norm of excellent teaching & $4.21 \pm 0.77$ & Very Important \\
14 & To foster faculty career development & $4.09 \pm 0.83$ & Important \\
15 & To facilitate effective pedagogy & $4.07 \pm 0.81$ & Important \\
16 & To serve personal needs & $3.83 \pm 1.01$ & Important \\
\hline
\end{tabular}

$\mathrm{SD}$, standard deviation.

Table 3. Level of importance of the following practices to the success of faculty development program

\begin{tabular}{llcc}
\hline Rank & \multicolumn{1}{c}{ Practice } & Mean \pm SD & Verbal interpretation \\
\hline 1 & Establishing a positive climate for teaching and learning & $4.45 \pm 0.71$ & Very important \\
2 & Providing resources & $4.37 \pm 0.71$ & Very important \\
3 & Teaching improvement workshops & $4.31 \pm 0.78$ & Very important \\
4 & Collaboration among faculty & $4.20 \pm 0.75$ & Important \\
5 & Providing technical support & $4.19 \pm 0.76$ & Important \\
6 & Networking among faculty and across academic and & $4.17 \pm 0.76$ & Important \\
7 & administrative departments & & Important \\
8 & Assessing needs & $4.15 \pm 0.79$ & Important \\
9 & Establishing learning communities & $4.13 \pm 0.77$ & Important \\
10 & Being visible and accessible & $4.05 \pm 0.93$ & Important \\
11 & Personal assessment program & $4.02 \pm 0.85$ & Important \\
\hline
\end{tabular}

$\mathrm{SD}$, standard deviation.

Table 4. Level of importance of the following factors in achieving faculty development program goals

\begin{tabular}{llcc}
\hline Rank & \multicolumn{1}{c}{ Factor } & Mean \pm SD & Verbal interpretation \\
\hline 1 & Skilled and dedicated staff support & $4.49 \pm 0.72$ & Very important \\
2 & Strong administrative support & $4.47 \pm 0.80$ & Very important \\
3 & Engaged and supportive faculty & $4.44 \pm 0.74$ & Very important \\
4 & Adequate budget & $4.43 \pm 0.81$ & Very important \\
5 & Ensuring the continuity of programs & $4.40 \pm 0.73$ & Very important \\
6 & Location and physical facilities & $4.31 \pm 0.75$ & Very important \\
7 & Strategic planning and goal setting & $4.29 \pm 0.84$ & Very important \\
8 & Timing of offered program & $4.28 \pm 0.85$ & Very important \\
9 & Climate of collaboration & $4.26 \pm 0.76$ & Very important \\
10 & Student support & $4.17 \pm 0.91$ & Important \\
11 & Grant funding & $4.15 \pm 0.84$ & Important \\
12 & Cultural tradition of support & $4.06 \pm 0.90$ & Important \\
13 & Providing food and refreshments & $3.36 \pm 1.22$ & Important \\
\hline
\end{tabular}

$\mathrm{SD}$, standard deviation. 
gram were achieved, the most important perceived factor was skilled and dedicated staff support $(4.49 \pm 0.72)$, followed by strong administrative support $(4.47 \pm 0.80)$ and engaged and supportive faculty $(4.44 \pm 0.74)$. The items that were evaluated as important but rated lowest were providing food and refreshments (3.36 \pm 1.22$)$, cultural tradition of support $(4.06 \pm 0.90)$, and grant funding $(4.15 \pm 0.84)$.

\section{Discussion}

Saudi universities are keen to achieve their strategic goals. One of these goals is to emphasize faculty development programs, especially in the light of continuously developing new pedagogical modalities and expectations. In order to achieve these goals, it is mandated that institutions expand and maintain regular, readily available, accessible, and comprehensive faculty development programs targeting faculty competency needs and educational objectives. Medical education in Saudi Arabia is challenged with the shortage of teachers who are adequately prepared to handle tasks in response to the emergent needs [2]. This was shown clearly in this study since the most important factor perceived in achieving faculty development program goals was skilled and dedicated staff support. Faculty should be engaged in all curricular and extracurricular activities, which require supervision and support by college administration.

In general, teachers view their task as imparting knowledge with disjunction between their practice and their beliefs. One of the primary goals of faculty development is to promote students' learning and motivate teachers to become better teachers. A medical teacher is considered a helper and a guide who fits into many different and simultaneous roles, such as being an instructor, a task master, facilitator, trainer, etc. Achievement of such ends may rest with individual teachers openly and actively engaging in teaching with reflection on their performance [15]. Reflection is considered a key concept of transformative learning theory, which is based on constructivist assumptions. Mezirow [16] considered transformative learning as a learning method that is based on our perceptions and experiences. He defined the process of learning as "the social process of constructing and appropriating a new or revised interpretation of the meaning of one's experiences as a guide to action." Our study confirms the importance of creating a climate and norm for excellent teaching.

McKeachie [17] argued that teaching skillfully may be less time consuming than teaching badly. It is well known that the need for effective learning increases as the time available to spend with students decreases. This was shown in our study as an important goal of faculty development program, which was to provide teaching improvement workshops and help faculty members learn excellent teaching methods.

According to Lueddeke [18], a fundamental education premise is that teaching influences student learning, and by improving educational knowledge and teaching practice, students should benefit. Evidence supporting the assumption that faculty development does impact on student learning and outcomes is accumulating. In our study, goals for faculty development programs included improved students' learning, helping faculty members learn appropriate and targeted teaching methods, and enhancing value of teaching effectiveness.

Teaching is a complex process and a demanding task. It is of paramount importance for the present-day teacher to become a part of the far-reaching changes that are taking place in the field of medical education. These changes include advances in learning styles and assessment methods, innovative curriculum models, and shifting from the conventional role of a teacher. These changes will not be achieved without a strong administrative support and adequate resources [19]. Our study clearly showed the importance of strong administrative support and adequate budget.

Faculty development is not just a "one-shot" intervention or "train the trainer" type of workshop. It is a continuous series of efforts that help faculty evolve their knowledge and skills as educators. This was reflected by the results of our study in which an important perceived factor in achieving faculty development program goals was ensuring the continuity of programs and strategic planning and goal setting. Comprehensive and intensive ongoing faculty development programs are necessary to increase teachers' knowledge and skills and reflection on practice. Protected time (i.e., time with salary support that faculty have for their non-educational responsibilities, such as research studies, manuscripts writing, or quality improvement initiatives) will allow participants to meaningfully test different approaches and use more student-focused activities. This will ultimately lead to improvement in student learning. This was also shown by our study as the timing of offered programs was among the most important factors in achieving faculty development program goals [20].

Limitations of this study include the small number of participants from certain universities. Future studies should initiate an urgent call to encourage participation in studies and research on the faculty development area of medical education. In addition, the results of 119 participants of King Saud bin Abdulaziz University for Health Science may influence the overall outcome. Furthermore, the results of the survey may vary depending on the faculty development program being offered to the survey participants. Therefore, an analysis of the current status of the faculty development program is warranted. An advantage of performing 
this research is creating ideas for future research on this important topic. For example, research may be conducted on the correlation between the recognition of faculty development and the difference in the educational environment at a university with a sample size similar to King Saud bin Abdulaziz University for Health Science.

In conclusions, the results of this study demonstrate that faculty members have positive perceptions regarding all aspects of faculty development programs. This study will raise awareness regarding the importance of such programs in sustaining educational vitality. We recommend the implementation and maintenance of comprehensive faculty development programs in Saudi universities. In addition, we recommend the development of a comprehensive curriculum for faculty development, which would also construct a solid ground for a diploma in medical education. Further studies regarding other aspects of faculty development programs, such as the current problems and needs of faculty members, contributing factors to achieve faculty development goals, barriers and obstacles impeding achieving such goals, and the effectiveness of existing faculty development programs, should be conducted. These studies are important to explore the needs and difficulties in implementing faculty development programs.

\section{Acknowledgments}

\section{Conflicts of interest}

No potential conflict of interest relevant to this article was reported.

\section{Author contributions}

Conceptualization: all authors; Data curation: HA, BS, LA; Formal analysis: HA, BS, AT, JN; Funding acquisition: HA, JN; Methodology, Investigation: all authors; Resources, Software: HA; Supervision, Validation: HA, JN; Project administration: HA, BS, LA; Visualization: HA, BS; Writing-original draft: HA, BS, JN; Writing-review \& editing: all authors.

\section{ORCID}

Hussein Algahtani, https://orcid.org/0000-0001-9484-9838

Bader Shirah, https: / / orcid.org/0000-0001-6493-2155

Lana Alshawwa, https://orcid.org/0000-0003-1993-6135

Ara Tekian, https://orcid.org/0000-0002-9252-1588

John Norcini, https://orcid.org/0000-0002-8464-4115

\section{References}

1. Bajammal S, Zaini R, Abuznadah W, Al-Rukban M, Aly SM,
Boker A, et al. The need for national medical licensing examination in Saudi Arabia. BMC Med Educ 2008;8:53.

2. Telmesani A, Zaini RG, Ghazi HO. Medical education in Saudi Arabia: a review of recent developments and future challenges. East Mediterr Health J 2011;17:703-7.

3. Dath D, Iobst W. The importance of faculty development in the transition to competency-based medical education. Med Teach 2010;32:683-6.

4. Simunovic VJ, Hren D, Ivanis A, Dorup J, Krivokuca Z, Ristic S, et al. Survey of attitudes towards curriculum reforms among medical teachers in different socio-economic and cultural environments. Med Teach 2007;29:833-5.

5. Hegde P. Faculty development trends in medical education: a review. South East Asian J Med Educ 2013;7:11-6.

6. Leslie K, Baker L, Egan-Lee E, Esdaile M, Reeves S. Advancing faculty development in medical education: a systematic review. Acad Med 2013;88:1038-45.

7. Bin Abdulrahman KA, Siddiqui IA, Aldaham SA, Akram S. Faculty development program: a guide for medical schools in Arabian Gulf (GCC) countries. Med Teach 2012;34(Suppl 1): S61-6.

8. Steinert Y. Staff development for clinical teachers. Clin Teach 2005;2:104-10.

9. Steinert Y, McLeod PJ, Boillat M, Meterissian S, Elizov M, Macdonald ME. Faculty development: a 'field of dreams'? Med Educ 2009; 43:42-9.

10. McLean M, Cilliers F, Van Wyk JM. Faculty development: yesterday, today and tomorrow. Med Teach 2008;30:555-84.

11. Cooke M, Irby DM, Sullivan W, Ludmerer KM. American medical education 100 years after the Flexner report. N Engl J Med 2006;355:1339-44.

12. Bhatnagar K, Srivastava K, Singh A. Is faculty development critical to enhance teaching effectiveness? Ind Psychiatry J 2010; 19:138-41.

13. Marks MB. Academic careers in medical education: perceptions of the effects of a faculty development program. Acad Med 1999;74(10 Suppl):S72-4.

14. Ahmady S. Faculty development in medical education: a comprehensive approach. Stockholm (SE): Karolinska Institutet; 2009.

15. Puri A, Graves D, Lowenstein A, Hsu L. New faculty's perception of faculty development initiatives at small teaching institutions. Int Sch Res Notices 2012;2012:726270.

16. Mezirow J. Education for perspectives transformation: women's re-entry programs in community colleges. New York (NY): Teachers College, Columbia University; 1978.

17. McKeachie WJ. Teaching tips: strategies, research, and theory 
for college and university teachers. 10th ed. Boston (MA): Houghton Mifflin; 1999.

18. Lueddeke GR. Professionalising teaching practice in higher education: a study of disciplinary variation and teaching-scholarship. Stud High Educ 2003;28:213-28.

19. Sorcinelli MD. Faculty development: the challenge going for- ward. Peer Rev 2007;9:4-8.

20. Davis D, O'Brien MA, Freemantle N, Wolf FM, Mazmanian P, Taylor-Vaisey A. Impact of formal continuing medical education: do conferences, workshops, rounds, and other traditional continuing education activities change physician behavior or health care outcomes? JAMA 1999;282:867-74. 